\title{
CONSTITUINTE, FINANCIAMENTO E DIREITO À EDUCAÇÃO: A VOZ DOS PROTAGONISTAS
}

\author{
Paulo de Sena Martins ${ }^{1}$ (D
}

RESUMO: Por meio das vozes dos protagonistas do processo constituinte - a dos parlamentares, em seus discursos no plenário e intervençóes nas audiências públicas da Subcomissão da Educação, Cultura e Esportes, e a dos representantes da sociedade civil que compareceram a essas sessôes para prestar seu depoimento - o trabalho resgata o processo de discussão que levou ao capítulo de educação da Constituição de 1988. Esse capítulo trouxe significativos avanços institucionais, no plano jurídico-constitucional, ao consagrar o direito à educação e estabelecer os pilares da política de seu financiamento.

Palavras-chave: Direito à educação. Financiamento. Manutenção e desenvolvimento do ensino. Salário-educação.

\section{CONSTITUENT, FINANCING AND RIGHT TO EDUCATION: THE PROTAGONISTS' VOICE}

ABSTRACT: From the voices of the constituent process' protagonists - those of parliamentarians' speeches in plenary and public hearings of the Subcommittee on Education, Culture and Sports and the civil society representatives who attended these hearings, this work rescues the discussion process that led to the education chapter of the 1988 Constitution. This chapter has brought significant institutional advances in the juridical-constitutional outline by enshrining the right to education and establishing the pillars of its funding policy.

Keywords: Right to education. Maintenance and development of education. "Salário-educação" (compulsory companies' payroll-based contribution to education).

\section{L'ASSEMBLÉE CONSTITUTIONNELLE, LE FINANCEMENT ET LE DROIT À L'ÉDUCATION : LA VOIX DES PROTAGONISTS}

Resumé : À partir de la voix des protagonistes des débats de l'Assemblée Constitutionnelle de 1988 - celle des parlementaires dans leurs discours aux séances plénière et des interventions aux audiences publiques de la sous-commission sur l'éducation, la culture et les sports et des

\footnotetext{
${ }^{1}$ Câmara dos Deputados, Área XV - Educação, Cultura e Desporto - Brasília (DF), Brasil.

E-mail: paulo.martins@camara.leg.br

DOI: 10.1590/ES0101-73302018193871
} 
représentants de la société civile qui ont assisté à ces auditions, cet article concerne le processus de discussion qui a entraîné le chapitre sur l'éducation dans la Constitution de 1988. Ce chapitre apporte des avancées institutionnelles significatives dans le cadre juridique et constitutionnel, en consacrant le droit à l'éducation et en établissant les piliers de sa politique de financement.

Mots-clés : Droit à l'éducation. Financement. Maintenance et Développement de l'éducation. Salaire-éducation.

\title{
Introdução: breve contexto da Constituinte de 1987-88
}

\begin{abstract}
o ensejo do 30 aniversário da Constituição de 1988 (BRASIL, 1988), dita 4 “Constituição Cidadã”, na expressão de Ulysses Guimarães (1988), o pre1 sente trabalho teve por escopo resgatar o processo de discussáo que levou a seu capítulo referente à educação, que, ao definir princípios a partir dos quais o ensino seria ministrado, os meios a serem disponibilizados e o dever do Estado, trouxe significativos avanços e consagrou, no plano jurídico-constitucional, o direito à educação.
\end{abstract}

De todas as conquistas do texto produzido pelos constituintes em 1988, merece destaque o direito à educação - estabelecido no art. 205 como regra geral. Nos termos do art. 208, $\$ 1^{\circ}$, o ensino obrigatório e gratuito foi reconhecido como direito subjetivo público. Além disso, cabe ressaltar os debates acerca do financiamento - meio importante para garantir a efetividade do direito.

Após uma intensa mobilização cidadã em 1984, com a campanha das "Diretas Já", foram conquistados caminhos para a participação popular na vida política e elaboradas pautas para a reconstrução institucional do país e a remoção do chamado "entulho autoritário".

Não sem obstáculos. Em 25 de abril de 1984, foi derrotada a emenda "Dante de Oliveira", que previa as eleições diretas.

As forças políticas e sociais que se opuseram ao regime cindiram-se ${ }^{1}$. Constitui-se, no momento seguinte, para disputar as eleiçóes indiretas, a "Aliança Democrática", que reunia o principal partido de oposição ao regime militar o Partido do Movimento Democrático Brasileiro (PMDB), ao lado de egressos do regime de exceção, dissidentes, que haviam formado a Frente Liberal.

Entre seus compromissos, figurava a instalação de uma assembleia nacional constituinte. Em documento firmado em 7 de agosto de 1984, assinado por Ulysses Guimarães, Tancredo Neves, Aureliano Chaves e Marco Maciel, intitulado "Compromisso com a Nação", obrigava-se a aliança à convocação de constituinte livre e soberana. 
Selava-se o pacto do qual não participavam os partidos de esquerda, como em outras transições, a exemplo da espanhola. A transição brasileira, na expressão de Souza (1988, p. 568), "instalou-se sobre os alicerces institucionais do regime autoritário, mais que sobre seus escombros”.

Com a eleição da chapa da "Aliança Democrática", seguida da trágica morte do presidente eleito, Tancredo Neves, a direção do primeiro governo civil pós-regime militar coube ao vice, José Sarney, que tomou posse em 1985, marcando a instituição da "Nova República".

Apesar do compromisso com a assembleia soberana, já sob o governo Sarney, atendendo à ideia divulgada por Tancredo Neves, foi editado, em julho, o Decreto no 91.450/85, que instituiu a "Comissáo Provisória de Estudos Constitucionais", composta de 50 membros de livre escolha do Chefe do Executivo². Alguns constituintes consideravam essa uma intervenção inadequada, posto que violaria a soberania da assembleia - posição que era contestada por seus membros ${ }^{3}$.

Em $1^{\circ}$ de fevereiro de 1987, foi instaurada a assembleia - o Congresso Constituinte, a partir de modelo que não se identificava com a tradicional moldura político-jurídica ${ }^{4}$.

Por iniciativa do Poder Executivo, foi apresentada proposta de emenda constitucional que se transformaria na Emenda Constitucional no 26, de 27 de novembro de 1985, que convocava Assembleia Nacional Constituinte, nos seguintes termos:

Art. 10 Os Membros da Câmara dos Deputados e do Senado Federal reunir-se-ão, unicameralmente, em Assembleia Nacional Constituinte, livre e soberana, no dia $1^{\circ}$ de fevereiro de 1987, na sede do Congresso Nacional (BRASIL, 1985).

$\mathrm{Na}$ sessão inaugural da assembleia, nos termos do art. $2^{\circ}$ da Emenda Constitucional 26/85, houve votação, ainda sob a condução do presidente do Supremo Tribunal Federal (STF), acerca da participação dos senadores eleitos em 1982, o que foi admitido pela assembleia.

O Congresso Constituinte aprovou o texto final em 22 de setembro e a Carta foi promulgada em 5 de outubro de 1988. Assim, somente três anos depois do início da Nova República, deu-se o encerramento do processo de transição democrática, com a aprovação da Constituição Cidadá.

\section{A Constituinte, os atores e o processo}

Os atores que exerceram papel importante no processo constituinte continuam sendo aqueles relevantes na atualidade: os Poderes do Estado (Executivo, 
Legislativo e Judiciário) e os Atores Sociais (entidades representativas de segmentos da comunidade educacional; gestores e conselhos educacionais; e associaçóes científicas).

Embora tenha sido do Poder Executivo a proposta de Emenda Constitucional $n^{\circ} 26 / 85$, que convocou a assembleia, foram os parlamentares-constituintes seus principais protagonistas, a lado da sociedade civil organizada (BACKES et al., 2009).

Ao mesmo tempo, o executivo sempre conservou seu poder de fogo e, uma vez que havia o interesse direto do presidente Sarney, de estabelecer seu mandato em cinco anos, muitas articulações e concessóes foram feitas a seus aliados, sobretudo ao chamado "Centrão", principal força a garantir a duração do mandato desejada pelo titular do Executivo.

No campo educacional, os atores foram se preparando para os debates e embates.

Por iniciativa da Associação Nacional de Pós-Graduação e Pesquisa em Educação (ANPEd), do Centro de Estudos, Educação e Sociedade (CEDES) e da Associação Nacional de Educação (ANDE), foi realizada, em setembro de 1986, em Goiânia, a IV Conferência de Educação, que reuniu mais de cinco mil educadores e teve como resultado uma série de propostas à Constituinte, expressas na Carta de Goiânia.

Constituiu-se o Fórum Nacional de Educação na Constituinte ${ }^{5}$, que depois passou a ser denominado Fórum Nacional em Defesa da Escola Pública (FNDEP).

Ao mesmo tempo, em abril de 1987, realizou-se, em Brasília, o XXI Congresso Nacional da Federaçáo Nacional de Estabelecimentos de Ensino (FENEN), que reuniu náo só o segmento empresarial representado pela entidade, mas também as escolas comunitárias, reunidas em torno da Campanha Nacional de Escolas da Comunidade (CNEC), e as escolas católicas, que compareceram às audiências públicas por meio de suas respectivas entidades - Associação de Educação Católica (AEC) e Associação Brasileira de Escola Superiores Católicas (ABESC) (PINHEIRO, 2001).

Também o Ministério da Educaçáo (MEC) criou um grupo de trabalho, "Educação e Constituinte", com representantes de suas secretarias - de ensino superior, de $1^{\circ}$ e $2^{\circ}$ graus, de educação física e desporto, além de representantes de organizaçóes da comunidade educacional — Fórum de Secretários de Educação, ANPEd, ANDE e representação de uma Prefeitura Municipal (Cabo, em Pernambuco) (DANC, 1987b, p. 209).

Esses protagonistas movimentavam-se no espaço de debate segundo regras que foram definidas no regimento interno da assembleia ${ }^{6}$. O presidente da Assembleia Nacional Constituinte, Ulysses Guimarães, eleito em 2 de fevereiro de 
1987, um dia após a instalação, já de início bloqueara a utilização das propostas da "Comissão Afonso Arinos" como referência para os trabalhos.

Conforme apontam Bonavides e Andrade (1989, p. 456-457):

A fórmula integrativa proposta para satisfazer a todos indistintamente se concebeu nos seguintes termos: criavam-se oito comissóes, cada qual subdividida em três subcomissóes. A par dessas comissóes e subcomissóes, haveria uma comissão central, a chamada comissão de sistematização, para a qual convergiria depois todo o trabalho das oito comissóes temáticas, mediante a ação coordenadora, condensadora e sistematizadora do relator. [...]

As comissóes e subcomissóes criadas, funcionaram de início como a espinha dorsal da constituinte, tendo sido o ponto de partida para a formulação do anteprojeto.

A ação de alguns constituintes teve impacto no processo geral e, consequentemente, na conformação, também, da pauta educacional.

O maior partido da Constituinte era o PMDB, agremiação marcada pela ambiguidade decorrente das múltiplas orientaçóes político-ideológicas dessa agremiação, como nota David Fleischer, para quem somente $40 \%$ da bancada era alinhada com a trajetória histórica do partido, que desde 1979 recebera ex-integrantes da Aliança Renovadora Nacional (ARENA): "Em contrapartida, as bancadas do PFL e do PDS são bem mais coerentes nesta dimensão" (FLEISCHER, 1987, p. 5).

Não só os alicerces institucionais, mas também os atores políticos eram egressos do antigo regime.

Daí a importância da ação do senador Mário Covas no exercício da liderança do PMDB na Constituinte, uma vez que lhe cabia a indicação de grande parte dos relatores das comissóes e subcomissóes. Assim, nessa fase, houve uma presença progressista desproporcional ao perfil conservador da maioria. Náo à toa, Gomes analisa essa fase em item intitulado "todo poder à minoria":

Esse esmiuçamento da composição ideológica dos grupos de trabalho torna-se muito relevante quando se relembra que os presidentes e os relatores das subcomissóes tinham assento reservado na grande comissão de sistematização, que cuidaria do processo constituinte perto da reta de chegada, antes das votaçóes de plenário (GOMES, 2014, p. 143).

Iniciada a fase das discussões na Comissão de Sistematização, não tardaria, como identificou José Afonso da Silva (AGÊNCIA SENADO, 2008), a "rebelião dos conservadores", com o advento do "Centráo", corrente conservadora 
que se colocou contra os rumos iniciais dessa comissão (que trabalhava a partir do material vindo das subcomissões e comissōes) ${ }^{7}$.

O constituinte Florestan Fernandes assinalaria: "vocês viram como se constituiu o Centrão, como o Centrão imobilizou o processo constituinte, deturpou-o, desviou-o de suas potencialidades e de seus fins" (FERNANDES, 1991, p. 34).

Em entrevista à Agência Senado, ao ensejo dos 20 anos da Constituição, o jurista José Afonso da Silva, que atuou na assessoria da liderança do PMDB, apontou:

Penso que a Constituição é razoavelmente equilibrada. Acho que o Centráo contribuiu para torná-la mais conservadora [...] A luta dos progressistas na Constituinte foi para criar um país mais justo, inclusive por via de uma reforma agrária profunda. Isso não foi possível. A maioria da Constituinte era conservadora, não obstante isso ela acabou produzindo uma Constituição razoavelmente progressista. A meu ver, é por isso que ela está conseguindo realizar razoável equilíbrio da vida nacional, o que nenhuma outra Constituição republicana conseguiu (AGÊNCIA SENADO, 2008).

O processo constituinte levou a esse desenho de uma constituiçáo democrática e comprometida com a supremacia do direito e a promoção da justiça (DALLARI, 2001).

\section{A Constituinte e a educação: primeiros debates parlamentares na fase da subcomissão}

Entre os colegiados temáticos, a Comissão VIII era a "Comissão da Família, da Educação, Cultura e Esportes, da Ciência e Tecnologia e da Comunicação", que se subdividia em três subcomissões, entre as quais estava a Subcomissão da Educação, Cultura e Esportes ${ }^{8}$, cujo presidente foi o deputado Hermes Zaneti (PMDB-RS), sendo indicado como relator o senador João Calmon (PMDB-ES). O relator-geral da Comissão VIII foi o deputado Artur da Távola (PMDB-RJ), tendo como presidente o senador Marcondes Gadelha (PFL-PB).

A subcomissão realizou quatro audiências públicas na área de educação, duas na área de cultura e duas na área de esporte, totalizando oito audiências públicas - o máximo permitido pelo Regimento Interno da Assembleia Nacional Constituinte (BARROS; ANDRES, 2009).

Em 21 de abril de 1987, na 9a reunião da subcomissão, iniciou-se a discussáo de mérito por parte dos parlamentares. 
Florestan Fernandes manifestou-se acerca das dicotomias constituição sintética versus constituição analítica ou constituição enxuta versus não enxuta ("molhada e salgada", em sua bem-humorada expressão), em seu recado inicial, ao reivindicar a efetividade do direito à educação:

Tenho a impressão de que devemos ser relativamente flexíveis com relação à extensáo da parte concernente à educaçáo na Constituição brasileira.

$[\ldots]$

Deveremos, nesse assunto e talvez em alguns outros, inovar no sentido de aumentar o número de normas constitucionais. Tomando certas inovaçóes imperativas, é provável que consigamos movimentar o carro. Não podemos ficar naquelas formulaçôes abstratas: "A educação é direito de todos e dever do Estado", e depois fecharmos os olhos à realidade concreta. [...]

Não devemos temer a extensão das propostas. Vai haver muito corte daqui para cima: na comissão, na Comissão de Sistematização, no Plenário. Não devemos cortar em nossa came; já vão cortar. Depois, teremos que ir a plenário, defender de novo as sugestóes que vamos apresentar aqui. Portanto, aproveitando a deixa que o pr6prio Constituinte Álvaro Valle levantou, contradizendo, em termos, a defesa de uma Constituição enxuta, com uma sugestáo concreta que não entraria numa Constituição enxuta, acho que a nossa Constituição deve ser molhada e salgada. Deve ser uma Constituição "peso-pesado". E, claro que não uma enciclopédia, porque senão ela também poderá o seu valor; deixará de ser instrumental na ação prática (apud DANC, 1987a, p. 142, grifos do autor).

O constituinte Louremberg Nunes Rocha repercutia essas palavras, introduzindo expressamente a questão dos recursos: "Não poderemos apenas apresentar, como disse o Constituinte Florestan Fernandes, bandeiras abstratas e gerais. Teremos que dar algum conteúdo a isso. E o conteúdo, me parece, passa pela destinação dos recursos" (apudDANC, 1987a, p. 142). Levantou também a ainda atual questão da destinação de recursos aos inativos que desfalcava os disponibilizados à manutenção e ao desenvolvimento do ensino:

Uma primeira questão a ser envolvida diz mesmo como a aposentadoria. Consta, nesses $13 \%$ de recursos da Uniáo para a educação, que estão incluídos e debitados aí 3\%, que correspondem ao pagamento das aposentadorias na área de educação. Se destacássemos esse percentual para a previdência e náo computássemos para a educação, não apenas sobrariam $3 \%$, mas se poderia com esses recursos talvez discutir (apud DANC, 1987a, p. 142-143).

Na mesma linha de argumentação, o senador Calmon apontou que um debate que se prolongaria seria o de se saber "o que é despesa com ensino, o que é despesa com alimentaçâo e outros itens controvertidos” (apud DANC, 1987a, p. 142-143). 
Essas intervençóes já indicavam, antes mesmo das audiências públicas com as entidades da sociedade civil, alguns pontos presentes nos debates, entre os quais destacavam-se os temas do financiamento e do direito à educaçáa ${ }^{9}$, que tinham aspectos específicos, mas eram, assim como outros assuntos, debatidos tendo como pano de fundo o conflito entre o público e privado (PINHEIRO, 2001). Para o então presidente da subcomissão, Hermes Zaneti, em entrevista concedida a Nalu Farenzena, da Revista Brasileira de Política e Administração da Educação (RBPAE), quando a Constituição completava 20 anos, a grande disputa "era entre a escola particular e a escola pública, esse pode ser considerado um divisor de águas. Outra grande disputa foi a fixação de um percentual mínimo da receita de impostos a ser destinado à educação" (FARENZENA, 2008, p. 353).

Assim, por exemplo, em relação ao direito à educação havia consenso quanto a sua titularidade pelos cidadãos — mas os defensores das instituiçóes privadas buscavam embaralhar o direito à educação e vinculá-lo a um alegado direito de escolha do tipo de instituição — de que ela deveria, independentemente de sua natureza, ser financiada com recursos públicos...

Dos grandes temas referentes ao financiamento, destacavam-se as disputas acerca da continuidade ou não da vinculação à manutenção e ao desenvolvimento do ensino, de recursos provenientes de impostos (assim como sua eventual ampliação e a definição de quais despesas deveriam ser consideradas ou excluídas do conceito) e a permanência ou não do salário-educação, assim como a definição de seu perfil. Com incidência transversal sobre esses aspectos - e outros — debatia-se mais acirradamente a destinação desses recursos, — se exclusivamente para o ensino público, como defendia o Fórum Nacional de Educação na Constituinte a partir da Carta de Goiânia, ou se admitida a aplicação em entidades comunitárias e confessionais ou mesmo nas instituições privadas lucrativas. A última ideia expressava-se no discurso dos representantes da FENEN e da ABESC. Este último defendia o conceito de uma escola pública não estatal (DANC, 1987b, p. 307).

$\mathrm{Na}$ mesma linha, o padre Agostinho Castejon, presidente da Associação Nacional de Educação Católica no Brasil (ANEC) sustentava a posição das escolas confessionais:

Há um slogan que diz: "dinheiro público para escola pública”. E concordamos com esse slogan, dependendo do que seja entendido por escola pública. Primeiro, quando se fala este slogan, junto com ele vem logo depois uma série de adjetivos: escola pública, estatal, gratuita, laica, religiosa. Concordamos com os dois primeiros critérios: escola pública e gratuita. Com os outros náo. Somos, portanto, contra a estatizaçáo $\cdot$ e contra o monopólio [...]. Defendemos uma escola pública estatal gratuita e de qualidade para todos. Defendemos também uma escola pública não estatal gratuita e de qualidade - como opção para aqueles que quiserem escolher esta escola (DANC, 1987b, p. 314). 
Desde a primeira reunião de discussão de mérito, o relator João Calmon manifestara-se pela manutenção, com ampliação, da vinculação de um percentual mínimo dos orçamentos públicos para o ensino.

O constituinte Ubiratan Aguiar propôs que se deixasse livre a iniciativa da escola particular, mas vedada sua manutenção ou sustentação pelo poder público, que deveria destinar os recursos públicos exclusivamente para as escolas públicas oficiais. Na mesma linha, os constituintes Chico Humberto, Sólon Borges dos Reis e Pedro Canedo defendiam a aplicação de recursos públicos exclusivamente nas escolas públicas, sendo livre a iniciativa privada - mas sem recebimento de recursos públicos.

Esse posicionamento gerou manifestação do constituinte Álvaro Valle, marcando o início da polêmica em torno do assunto ${ }^{10}$ :

Pela terceira vez, eu ouço que os recursos públicos devem ser destinados exclusivamente à escola pública. Para que não passe essa referência como algum pensamento unânime desta Subcomissão, eu gostaria de fazer uma restrição à ideia. Eu acredito que os recursos públicos devam ser destinados à educação. A escola pública no Brasil é uma escola geralmente ineficiente e cara. Quando se abre uma escola pública para mil crianças, mais do que está se dando escola a mil crianças, está se tirando mais ou menos de quatro mil outras, porque a escola privada, normalmente, custa pelo menos cinco vezes mais barato do que a escola pública (apud DANC, 1987a, p. 145).

Na mesma linha, o constituinte Louremberg Nunes Rocha contraditaria as intervenções mencionadas:

Haverá locais, nessa diversidade que é este Pais, em que existirá um abnegado tocando uma escola particular que é a solução daquela comunidade. Por que é que não se poderia discutir a possibilidade de se dar alguma ajuda via Estado a esse abnegado que está lá? (apud DANC, 1987a, p. 163).

O constituinte Aécio de Borba sugeriu destinar, pelo menos, mais de $50 \%$ daquilo que ficasse estipulado na Constituição, nas disposiçóes transitórias, "para que durante um prazo de 4 anos se constituísse num recurso oportuno para a extinção do déficit de escolaridade existente no País" (apud DANC, 1987a, p. 145).

Ainda antes das audiências, a questáo do financiamento seria o tema da $11^{\text {a }}$ reunião, em 22 de abril. O constituinte Octávio Elísio assinalava:

O Ministério da Educação, em decorrência da incorporação da Emenda Calmon à Constituição, quase triplicou seu orçamen- 
to, que é, hoje, o segundo orçamento da União, e, apesar disto, todas as universidades públicas brasileiras estão paradas há trinta dias por falta de recursos de custeio, por falta de recursos para investimento e por reivindicaçóes salariais de professores e funcionários. [...] O outro ponto, especialmente em se tratando de escolas de $1^{\circ}$ e $2^{\circ}$ Graus, como se referiu o nosso ilustre Constituinte, é que não podemos esquecer que o salário-educação, que é um recurso público arrecadado às folhas de pagamento das empresas, tem sido maciçamente canalizado para bolsas de estudo (apud DANC, 1987a, p. 162).

O constituinte Ubiratan Aguiar ressaltaria que a Emenda Calmon proporcionara um "salto gigantesco", saindo-se de um percentual inferior a 5 para $13 \%$, em que pesassem as "distorçóes verificadas com a inclusão, como se fora para a educação, daqueles recursos despendidos com a alimentação, com a saúde, e outros recursos que se perdem ao longo das rubricas orçamentárias do MEC" e que "não se podem figurar como recursos destinados à educação, à manutenção e ao desenvolvimento da rede de ensino" (apud DANC, 1987a, p. 162). Essa preocupação de vários dos atores foi mais bem expressa na Carta de Goiânia para a Constituinte, que previa que a merenda escolar ou qualquer outro programa assistencial a ser desenvolvido nas escolas deviam contar com verbas próprias, desvinculadas dos recursos orçamentários para a educação stricto sensu, porém gerenciadas por órgãos da área educacional (DANC, 1987b, p. 296).

Esses temas, referentes ao salário-educação e que seriam retomados nas audiências públicas, já eram examinados pelos pesquisadores do campo educacional.

Ainda sob o regime da Constituição de 1969, Melchior já defendia que fosse constitucionalizada a divisão entre estados e municípios, da distribuição da parcela de 2/3 do salário-educação (MELCHIOR, 1985).

Velloso propunha que o salário-educação incidisse não mais sobre a folha de pagamento, mas sobre a receita bruta das empresas, removendo-se o ônus sobre o fator trabalho (VELLOSO, 1989). Em relação aos recursos públicos carreados para as escolas privadas, o autor afirmava (VELLOSO, 1988, p. 362):

Uma importante forma de subsídio é o chamado Sistema de Manutenção de Ensino - SME, que usa recursos do salário-educação, a principal fonte singular de verbas para o desenvolvimento do ensino público de ${ }^{\circ}$ grau. As bolsas e as aquisiçóes de vagas do SME, que hoje correspondem nominalmente a quase $1 / 3$ das matrículas na rede privada de $1^{\circ}$ grau, geralmente concedidas a aluno não-carentes, já que as escolas particulares não costumam concentrar-se nas periferias urbanas e em outras regióes pobres. 
Em longo pronunciamento, no qual resgatou o embate entre os pioneiros da escola nova e as escolas particulares, bem como a gênese da antiga Lei de Diretrizes e Bases da Educação Nacional (LDB), o constituinte Florestan Fernandes pontuou:

Esse processo de aceleração da acumulação capitalista na esfera da educação não ocorreria sem a proteção oficial. A proteção oficial que apareceu sob a forma de empréstimos privilegiados. Associação de donos de escolas com os donos do poder; isenção de taxas e impostos, e várias outras formas de corrupçáo ativa e passiva.

[...] Portanto, é uma situação dramática, temos de pensar no ensino público em novas bases; temos que pensar que o Estado não deve dividir os seus recursos com a indústria do ensino, nem tampouco financiar o ensino convencional, que visa o controle de mentes e coraçóes, mas que deve investir maciçamente para que tenhamos uma escola - como disse o Professor Octávio Elísio em sua bela exposição — que tenha boa qualidade, que esteja ao alcance de todos e que forme o cidadão. $\mathrm{O}$ cidadão, no Brasil, ou será formado pela escola pública de primeira qualidade ou não aparecerá nunca (apud DANC, 1987a, p. 163-164).

Era a voz desse cidadáo que passaria a ser ouvida na próxima etapa de debates na subcomissão (Quadro 1).

\section{Direito à educação e financiamento nas audiências públicas da subcomissão}

A partir de 23 de abril (12a reunião), realizaram-se as primeiras audiências públicas da subcomissão, concluídas em 30 de abril ${ }^{11}$. Apesar de o resultado oriundo da subcomissão não ser definitivo e ter de enfrentar outras arenas que o filtrariam - a Comissão Temática 8 , a Comissão de Sistematização e o plenário, esse processo gerou grande parte do conteúdo da futura Carta e afastou o temor de que se concebesse uma Constituição elitista, sem participação popular e da sociedade civil organizada.

Além das sugestóes em audiências, as entidades trouxeram a realidade às portas dos constituintes. $\mathrm{O}$ fato de haver se instaurado o processo náo significava que o país respirasse um momento idílico: vivia-se prolongada greve das universidades federais. Também nos municípios havia greves do magistério que estavam sendo reprimidas ${ }^{12}$.

$\mathrm{Na} 12^{\mathrm{a}}$ reuniāo, Elba de Sá Barreto (ANDE) afirmava que o "direito à educação tem sido escamoteado justamente à maioria da população" e reivindicava uma maior participação da União: 


\section{Quadro 1}

Audiências públicas da Subcomissão da Educação,

Cultura e Esportes na Assembleia Constituinte que debateram a educação, 1987.

\begin{tabular}{|c|c|c|}
\hline $\begin{array}{l}\text { Audiência } \\
\text { pública/data }\end{array}$ & Entidade/personalidade & Representante(s) \\
\hline \multirow{5}{*}{$\begin{array}{l}\text { 23/04/1987 } \\
\text { manhã }\end{array}$} & $\begin{array}{l}\text { Associação Nacional } \\
\text { de Educação (ANDE) }\end{array}$ & $\begin{array}{l}\text { Elba Siqueira de Sá Barreto } \\
\text { (presidente) e Jarbas Novelino Barato }\end{array}$ \\
\hline & $\begin{array}{l}\text { Associaçáo Nacional de Docentes do } \\
\text { Ensino Superior (ANDES) }\end{array}$ & $\begin{array}{l}\text { Newton Lima Neto (presidente) e } \\
\text { Miriam Limoeiro Cardoso }\end{array}$ \\
\hline & $\begin{array}{c}\text { Federação Brasileira das } \\
\text { Associaçôes de Professores de } \\
\text { Educação Física (FBAPEF) }\end{array}$ & Cláudio Boschi \\
\hline & $\begin{array}{c}\text { Associação Nacional de } \\
\text { Profissionais de Administração da } \\
\text { Educação (ANPAE) }\end{array}$ & Maria Beatriz Moreira Luce \\
\hline & $\begin{array}{c}\text { Sociedade Brasileira para o Progresso } \\
\text { da Ciência (SBPC) }\end{array}$ & Luiz Antônio Cunha \\
\hline \multirow{3}{*}{$\begin{array}{l}\text { 23/04/1987 } \\
\text { tarde/noite }\end{array}$} & $\begin{array}{l}\text { Ministério da Educação e Cultura } \\
\text { (MEC) }\end{array}$ & $\begin{array}{c}\text { Oswaldo Della Giustina (chefe } \\
\text { de gabinete do ministro Jorge } \\
\text { Bornhousen)/Ernany Bayer (SESU) }\end{array}$ \\
\hline & Conselho Federal de Educação (CFE) & Fernando Gay da Fonseca \\
\hline & $\begin{array}{l}\text { Fórum Nacional de Secretários de } \\
\text { Educação }\end{array}$ & Gilda Poli Rocha Loures \\
\hline \multirow{4}{*}{$\begin{array}{l}\text { 28/04/1987 } \\
\text { manhá }\end{array}$} & $\begin{array}{c}\text { Confederação dos Professores do } \\
\text { Brasil (CPB) }\end{array}$ & Tomaz Gilian Deluca Wonghon \\
\hline & $\begin{array}{c}\text { Federação das Associaçóes de } \\
\text { Servidores das Universidades } \\
\text { Brasileiras (FASUBRA) }\end{array}$ & $\begin{array}{l}\text { Vânia Maria Galvão de Carvalho } \\
\text { (presidente) e José Ferreira de Alencar }\end{array}$ \\
\hline & $\begin{array}{c}\text { Sociedade Estudos e Atividades } \\
\text { Filosóficas (SEAF) } \\
\end{array}$ & Henrique Nielsen Neto \\
\hline & $\begin{array}{c}\text { Conselho de Reitores das } \\
\text { Universidades Brasileiras (CRUB) }\end{array}$ & Rodolfo Joaquim Pinto da Luz \\
\hline \multirow{3}{*}{$\begin{array}{l}28 / 04 / 1987 \\
\text { tarde }\end{array}$} & $\begin{array}{l}\text { Uniāo Brasileira dos Estudantes } \\
\text { Secundaristas (UBES) }\end{array}$ & Rovilson Robbi Britto \\
\hline & $\begin{array}{c}\text { Associação Nacional de Pós- } \\
\text { Graduação e Pesquisa em Educação } \\
\text { (ANPEd) }\end{array}$ & $\begin{array}{l}\text { Osmar Fávero (presidente) } \\
\text { e Jacques Veloso }\end{array}$ \\
\hline & $\begin{array}{l}\text { Centro de Estudos, Educação e } \\
\text { Sociedade (CEDES) }\end{array}$ & Elizabeth Camargo \\
\hline \multirow[b]{2}{*}{ 29/04/1987 } & Centro de Trabalho Indigenista (CTI) & Marina Kahn Villas Boas \\
\hline & $\begin{array}{l}\text { Associação Brasileira de Escola } \\
\text { Superiores Católicas (ABESC) }\end{array}$ & Waldemar Valle Martins \\
\hline
\end{tabular}




\section{Quadro 1}

Continuação.

\begin{tabular}{|c|c|c|}
\hline $\begin{array}{l}\text { Audiência } \\
\text { pública/data }\end{array}$ & Entidade/personalidade & Representante(s) \\
\hline \multirow{6}{*}{ 29/04/1987 } & $\begin{array}{c}\text { Campanha Nacional de Escolas da } \\
\text { Comunidade (CNEC) }\end{array}$ & Felipe Thiago Gomes \\
\hline & União das Nações Indígenas & Ailton Krenak \\
\hline & $\begin{array}{c}\text { Organização Nacional de Entidades de } \\
\text { Deficientes Físicos }\end{array}$ & Paulo Roberto Guimarães Moreira \\
\hline & $\begin{array}{c}\text { Federação Nacional de } \\
\text { Estabelecimentos de Ensino (FENEN) }\end{array}$ & Roberto Dornas \\
\hline & $\begin{array}{c}\text { União Nacional } \\
\text { dos Estudantes (UNE) }\end{array}$ & Gisela Mendonça \\
\hline & $\begin{array}{l}\text { Associaçáo de Educaçáo } \\
\text { Católica (AEC) }\end{array}$ & Padre Agostinho Castejon \\
\hline \multirow{10}{*}{$30 / 04 / 1987$} & $\begin{array}{l}\text { Uniâo dos Diretores de Escolas do } \\
\text { Magistério Oficial (UDEMO) }\end{array}$ & Francisco Antônio Poli \\
\hline & $\begin{array}{c}\text { Federação dos Trabalhadores em } \\
\text { Estabelecimentos de Ensino da Região } \\
\text { Sul (FETEE SUL) }\end{array}$ & $\begin{array}{l}\text { José Roberto Torres Machado e } \\
\text { Alcides de Carvalho }\end{array}$ \\
\hline & $\begin{array}{c}\text { Federaçáo Interestadual dos } \\
\text { Trabalhadores em Estabelecimentos } \\
\text { de ensino (FITEE) }\end{array}$ & $\begin{array}{c}\text { Wellington Teixeira Gomes e Carlos } \\
\text { Magno Machado }\end{array}$ \\
\hline & Conselho Federal de Farmácia & Carlos Couto de Castelo Branco \\
\hline & $\begin{array}{c}\text { Centro de Estudos } \\
\text { Afro-Brasileiros (CEAB) }\end{array}$ & Wladimir de Souza \\
\hline & Conselho da Comunidade Negra & Hélio Santos \\
\hline & $\begin{array}{l}\text { Comissão Pró-Federação Nacional de } \\
\text { Arte-educadores }\end{array}$ & Laís Aderne \\
\hline & $\begin{array}{l}\text { Associaçáo Nacional dos Professores } \\
\text { de Prática de Trabalho }\end{array}$ & Mary Yclea \\
\hline & $\begin{array}{c}\text { Organizaçáo das } \\
\text { Cooperativas Brasileiras }\end{array}$ & Guntolf Van Kaick \\
\hline & Organizações Evangélicas & Ulysses Panisset \\
\hline $13 / 05 / 1987$ & MEC & Ministro Jorge Konder Bornhausen \\
\hline $\begin{array}{l}18 / 05 / 1987 \\
\text { (reunião } \\
\text { especial) }\end{array}$ & $\begin{array}{l}\text { Professores Paulo } \\
\text { Freire e Moacir Gadotti }\end{array}$ & \\
\hline 20/05/1987 & Professor Juan Tedesco & \\
\hline
\end{tabular}


Frente às extremas discrepâncias de atendimento em ensino fundamental é preciso que a União entre também, e não de forma parcelada, pingada, como tem entrado onde muito mais no caráter de suplência fica diluído a sua participação. É preciso que a União entre no sentido de garantir, de qualquer modo, que esse direito seja assegurado à população. [...] é preciso que as instâncias que agrupam maiores recursos financeiros humanos e institucionais se envolvam no sentido de que este direito da população seja assegurado. Então, é mais um compromisso nacional do que uma divisão de responsabilidade por instâncias em que uma deixa para a outra e se exime da responsabilidade (apud DANC, 1987a, p. 174).

O outro representante da ANDE, Jarbas Novelino Barato, defendia que ficasse claro na nova Constituição que "as pessoas que não puderam ir à escola dos 7 aos 14 anos, ou dos 6 aos 18 anos, não perderam o direito à educação fundamental, porque isso é um direito permanente, é um direito que não prescreve com a idade" (apud DANC, 1987a, p. 173).

As representações da Associação Nacional de Docentes do Ensino Superior (ANDES), da União Brasileira dos Estudantes Secundaristas (UBES) e da ANPEd posicionaram-se, também, no sentido de que a educação é um direito de todos os cidadãos brasileiros. A representante do CEDES lembrava que, nos termos da Carta de Goiânia, tratava-se de direito ao ensino público, gratuito e laico, em todos os níveis de escolaridade, sem distinção de sexo, raça, idade, convicção religiosa, filiação política ou classe social.

Maria Beatriz Luce (Associação Nacional de Profissionais de Administração da Educação - ANPAE) retoma a questão de que o conteúdo do direito à educação passa pelo problema dos $\operatorname{recursos}^{13}$ :

Sintetizando a contribuição da ANPAE aos Srs. Constituintes, gostaria de destacar três aspectos: em primeiro lugar, a ANPAE se posiciona, tal qual as entidades que aqui estiveram, e por isso mesmo ela também faz parte do fórum de entidades de Educação na Constituinte. A ANPAE se posiciona, absolutamente, pelo reconhecimento do direito à educação gratuita, pública, laica e de qualidade em todos os níveis e modalidades de ensino, como um direito de todos os cidadáos brasileiros. [...]

Dizendo isso, introduz-se, de imediato, um segundo ponto que gostaríamos de destacar, dada a especificidade do trabalho da nossa Associação: é que o direito à educação e o dever do Estado em prover esse direito requerem absolutamente o comprometimento das verbas públicas com a educaçáo pública em sentido de exclusividade. Entendemos que é absolutamente necessário garantir na Constituiçáo a explicitação dos direitos e deveres fundamentais acerca da educaçáo, bem como os meios requeridos para o cumprimento desse direito e desse dever (apud DANC, 1987a, p. 187). 
Em diálogo com a expositora, o senador Calmon relatou que estava se travando uma batalha no STF, que examinava a representação de prefeitos do Estado de Sáo Paulo, que arguiam a inconstitucionalidade da lei que regulamenta a Emenda Calmon, ao mesmo tempo em que apelava para que todas as entidades da área educacional a ele se juntassem para requerer o aumento do percentual da União.

Havia motivos para tanto. As entidades signatárias da Carta de Goiânia haviam estacionado no patamar entáo vigente da Emenda Calmon - 13\% dos impostos da União. Poucas eram as propostas diferentes ${ }^{13}$.

Em discurso proferido em 13 de agosto de 1987, o constituinte Joáo Calmon fundamentava seu receio:

Temos embutida na Constituição que estamos elaborando a reforma tributária, que vai distribuir de maneira mais equitativa a receita de impostos. A União deverá perder, no mínimo, 20\% da sua atual receita tributária.

Como isso vai ocorrer, não podemos permitir que a Educação sofra tão revoltante desfalque.

Fizemos os cálculos e chegamos à conclusão de que deveríamos propor o aumento de 13 para $18 \%$. Nem todos sabiam - eu, sim que, na Comissão do Sistema Tributário, seus ilustres membros, naturalmente inspirados por propósitos patrióticos, haviam decidido aprovar artigo que proíbe terminantemente a vinculaçáo de qualquer verba orçamentária para qualquer finalidade, sem abrir nenhuma exceção. Esse seria um golpe mortal nessa luta, que data de mais de meio século, que vem desde 1934 (apud DANC, 1987e, p. 5169, grifo do autor).

A vinculação, aprovada na subcomissão, foi mantida nos dois relatórios da Comissão 8 (única que não conseguiu aprovar um anteprojeto, após tumultuada sessão final, ficando o encargo para o relator-geral da sistematização), bem como no anteprojeto e no projeto da Comissão de Sistematização, apresentados em junho e julho, respectivamente. Ocorre que os relatórios dessa comissão, no título relativo à tributação e aos orçamentos, vedavam qualquer vinculação de receita. A convivência desse dispositivo com o da vinculação de recursos para o ensino podia sugerir que, na área educacional, seria permitida uma exceção. Em agosto, o substitutivo do relator da Comissão de Sistematização realizava uma manobra contra a vinculação - embora fosse prevista a destinação dos recursos de manutenção e desenvolvimento do ensino, estes seriam definidos em planos plurianuais. E o título da ordem social náo mencionava o assunto, remetido às disposiçóes transitórias - e, apesar de nos planos plurianuais os valores não terem sido fixados, estes seriam de $18 \%$ para a União e de $25 \%$ para os entes subnacionais (VELLOSO, 1988; CALMON, 1991). 
O senador Calmon afirmou: "procurei alarmado o relator Bernardo Cabral que ficou 'estupefato e profundamente irritado diante de minha revelação'. Ele prometeu-me solenemente corrigir essa grave falha no próximo projeto 'Bernardo Cabral'” (CALMON, 1991, p. 41) ${ }^{14}$.

Outro importante tema abordado, embora sem muitas manifestaçóes, foi o referente ao salário-educação. Além da mencionada intervenção do constituinte Octávio Elísio, na $11^{\text {a }}$ reunião, Tomaz Wonghon, da Confederação dos Professores do Brasil (CPB) defendeu, na 15ª reunião, em 28 de abril de 1987, que os recursos do salário-educação fossem destinados exclusivamente ao ensino público oficial de $l^{\circ}$ grau, sendo vedado o seu emprego para qualquer outro fim.

Instado pelo constituinte Octávio Elísio, Jacques Velloso, que integrava a representação da ANPEd na $15^{\text {a }}$ reuniáo, esclarecia:

\begin{abstract}
Mais recentemente, com a mudança na legislação, diminuiu o número de alunos financiados diretamente pelas empresas e cresceu o volume de recursos que sobravam no salário-educação, recursos que eram destinados pelas empresas a bolsas, ou seja, em resumo, as empresas, hoje, optam, preferem, de acordo com a legislaçáo, destinar num volume gigantesco. de recursos a bolsas de estudo, ou seja esses $57 \%$ restantes - um resto maior do que a metade do salário-educação, é destinado a bolsas de estudo [...].

Hoje, o total dos recursos do salário-educação é ponderável, pois em 1986 foi da ordem de 12 bilhóes de cruzados, ou seja, cerca de 35\% da despesa realizada pelo Ministério da Educação no ano passado. Destes 12 bilhóes de cruzados, mais da metade financia bolsas de estudo, em vez de financiar o ensino público (apud DANC, 1987b, p. 267-268).
\end{abstract}

Osmar Fávaro completava que, em 1984, o recurso do salário-educação, em valores absolutos, "representava a $6^{\mathrm{a}}$ arrecadação do país. Estava na frente dela apenas a arrecadação tributária do Estado de São Paulo, Imposto de Renda, e coisas desta ordem" (apud DANC, 1987b, p. 274).

O constituinte Sólon Borges dos Reis expressava preocupação com a proposta de eliminação do salário-educação na Comissão de Tributação (apud DANC, 1987b, p. 149).

Os anais registram, ainda, as seguintes manifestaçóes:

O SR. CONSTITUINTE ÁTILA LIRA - [...] Quero aqui lembrar, quanto ao problema de recursos para a educação, que todos os dias estou conversando com os Srs. Constituintes que estấo tratando do sistema tributário, e o pensamento deles é o de restringir ou tirar alguns tributos ou contribuiçóes que nos ajudam. A mentalidade da Subcomissão de Tributos, Participação e 
Distribuição das Receitas é exclusivamente pragmática, ao ponto de procurar acabar com o FAS, salário-educação e restringir a nossa capacidade de arrecadaçáo a poucos tributos.

[...] O SR. CONSTITUINTE LOUREMBERG NUNES ROCHA - [...] Realmente, é importante esse alerta do nobre Constituinte Átila Lira. [...] Se nos tiram o salário-educação para uma outra regulamentação, com relação às despesas das empresas, se outras contribuiçóes saem, realmente, o bolo da educação começa a ficar muito restrito. $\mathrm{O}$ meu pensamento é que deve haver um acompanhamento dos debates, pressionarmos os nossos colegas e dizermos que estamos lutando por isso e por aquilo (apud DANC, 1987c, p. 176).

Em seu depoimento, o ministro Jorge Bornhausen defendeu a "necessidade da permanência do salário-educação como instrumento fundamental para o processo de desenvolvimento educacional no Brasil" (apud DANC, 1987d, p. 234-235). Ao mesmo tempo, propugnou pela atuação somente subsidiária, enquanto for necessário, da União no processo educacional.

Aspecto importante acerca do critério de arrecadação do salário-educação seria trazido em seguida, em resposta ao constituinte Cláudio Ávila. O ministro rejeitou a contribuição pelo lucro bruto, defendendo que seria melhor a manutenção da taxação sobre a folha de contribuição das empresas. Defendeu, ainda, a opção da distribuição de bolsas:

Então, ela tem o direito de escolher uma escola credenciada, e não pode escolher uma escola pública, porque a escola pública já é gratuita. Então, ela indica, — mas é bom que se ressalte que todo o salário-educação arrecadado, em 1986, apenas $600 \mathrm{mi}$ lhóes de cruzados foram aplicados em bolsas, portanto, menos de $6 \%$ do valor do salário-educação que foi recolhido aos cofres dos Estados, Municípios e União. Então, penso ser uma opção legal que deve ser respeitada (apud DANC, 1987d, p. 243).

Assim como no caso da vinculação, os termos em que foi constitucionalizado o salário-educação eram genéricos o suficiente para adiar qualquer conflito público-privado. A possibilidade de compra de vagas, por meio do Sistema de Manutenção de Ensino (SME), somente despareceu com a Emenda Constitucional no $14 / 96$.

\section{Conclusão}

Em 23 de maio, houve a votação do substitutivo do relator João Calmon, sendo a apresentação da redação final do anteprojeto em 25 de maio de 1987. 
A Comissão 8 teve de apreciar dois relatórios, de lavra, respectivamente, dos constituintes Arthur da Távola, seu relator, e Marcondes Gadelha, seu presidente.

$\mathrm{O}$ direito à educação é defendido em face do Estado, que tem o dever de ofertá-la.

As fontes orçamentárias que até hoje constituem os pilares de financiamento também são garantidas perante o Estado. Assim, como não há antagonismo entre o público e o privado no que se refere ao núcleo das propostas de vinculação da receita de impostos e continuidade do salário-educaçáo (embora com eventuais divergências quanto a sua regulamentação), esses temas tenderam à convergência dos atores educacionais. Os obstáculos à vinculação ou ao salário-educação localizavam-se nas comissóes que discutiam tributação, seguridade e saúde. Em relação a esta última, vale conferir o depoimento do senador Calmon acerca da tentativa de incluir na manutenção e no desenvolvimento do ensino despesas assistenciais e de saúde:

Tanto no projeto que viera da Comissão de Sistematização por nós aprovado e consubstanciado no "Cabral III", quanto na proposta do Centrão, a vinculação foi mantida em favor da Educação. Serra ainda esboçou a tentativa de levar a questão a plenário, mas o único risco sério que a vinculação sofreu partiu de outra área. Pouco antes da votação do capítulo da educação, os setores mais ligados à área de Saúde propuseram ampliar o alcance das despesas, previstas no texto original, destinadas à educaçấo. [...] Reagi a essa tentativa que, a meu ver, desvirtuaria inteiramente a proposta original [...].

À noite, em nova reuniāo, reformulamos um novo plano, com a ajuda preciosa do líder Mário Covas. Ficou assentado que as despesas não ligadas ao ensino, como alimentação e assistência médica, passariam a ser custeadas pelo novo fundo de seguridade, que incorporava a receita do Finsocial, assim a educação seria preservada desse novo golpe (CALMON, 1991, p. 43).

A divergência que levou ao impasse, a ponto de inviabilizar até mesmo a votação de qualquer relatório da Comissão 8 , a grande questão como afirmou Zaneti, era o conflito público-privado, o que no caso do financiamento se expressou na defesa ou não da exclusividade de destinação dos recursos públicos às escolas públicas e n própria definição de escola pública, que as entidades comunitárias, filantrópicas e confessionais tentaram alargar com a defesa do conceito de público não estatal.

Ao final, houve um acordo para a aprovação do capítulo da educação, em 20 de maio de 1988, a partir de um "emendáo" assinado por todos os líderes e que obteve 433 votos a favor, 3 abstençóes e 2 votos contrários. Para o senador Calmon, o texto levado a plenário "incorporava todas as conquistas, todos os prin- 
cipais pontos do anteprojeto" que apresentara um ano antes à subcomissáo, quase sem alterações (CALMON, 1991, p. 43).

A Constituição de 1988 é a matriz dos avanços sociais nas três últimas décadas e, especificamente, da garantia do direito à educação e do estabelecimento das bases para seu financiamento com a manutenção da regra e do princípio ${ }^{15} \mathrm{da}$ vinculação constitucional à manutenção e ao desenvolvimento do ensino (MDE) e a continuidade do salário-educaçấo. As emendas constitucionais que alteraram esse capítulo ou introduziram temas a ele relacionados no Ato das Disposiçóes Constitucionais Transitórias (ADCT) — Emenda 11 (admissão de profissionais estrangeiros nas universidades), Emenda 14 (Fundo de Manutenção e Desenvolvimento do Ensino Fundamental e de Valorização do Magistério - FUNDEF) e Emenda 53 (Fundo de Manutençáo e Desenvolvimento da Educação Básica - Fundeb), mantiveram o espírito da Carta de 1988. As tensóes e os obstáculos normativos viriam das emendas de desvinculação (com o Fundo Social de Emergência - FSE; o Fundo de Estabilização fiscal — FEF; e a Desvinculação das Receitas da União - DRU), que deixaram de ter efeitos para a educação, com a Emenda Constitucional no 59, até o advento da Emenda Constitucional no 95 (teto fiscal para despesas primárias) — que, por 20 anos, suspendeu a regra da vinculação e configurou o instrumento de uma agenda desconstituinte - no sentido de que tanto tende a desconstituir direitos que vinham ganhando espaço de efetividade como se opóe frontalmente às disposiçôes, aos métodos e ao espírito da Constituinte de 1987.

\section{Notas}

1. Alguns setores a persistiram nas "Diretas Já" (os partidos da esquerda, como o PT, e, inicialmente, o movimento "Só Diretas", com segmentos do PDT e PMDB, mas que acabou se dissolvendo), enquanto outros - o que incluía, também, os partidos comunistas, renderam-se ao pragmatismo que buscava pela via da participaçáo no colégio eleitoral, o fim do ciclo autoritário. No dia 15 de janeiro de 1985, o Colégio Eleitoral reuniu-se e Tancredo Neves foi eleito presidente para um mandato de 6 anos com 480 votos $(72,4 \%)$ contra 180 dados a Maluf (27,3\%). Houve 26 abstenções, principalmente de parlamentares do PT, que foram orientados a votar nulo pelo diretório nacional do partido. Destoaram os deputados Bete Mendes, Airton Soares e José Eudes, que votaram na chapa da Aliança Democrática e acabaram sendo expulsos do PT (CARVALHO, 2016).

2. Essa comissão ficou conhecida como Comissão "Afonso Arinos", em alusão a seu presidente.

3. Para Lamounier, a comissão se inseria em uma brecha entre uma concepção "rousseauísta" da assembleia, como se fosse uma assembleia originária e outra em que, a partir da ideia de que não houve um processo revolucionário de ruptura, o constituinte deveria ser aquele que o Poder Legislativo - eleito sob o regime anterior - convocasse, isto é, uma constituinte congressual (LAMOUNIER, 1986). Essa ideia, de não-ruptura, estava expressa, inclusive, no pronunciamento 
do ministro Moreira Alves, do STF, ao presidir os trabalhos iniciais de instalação da assembleia (BONAVIDES \& ANDRADE, 1989). Juristas progressistas defendiam que a "decadência" do regime de 1964 justificaria a presença de um poder constituinte "originário" no processo, e não simplesmente de um "derivado" (ARAUJO, 2013). Esse documento seria arquivado e não remetido à assembleia, uma vez que Ulysses Guimarães sinalizara que iria devolvê-lo. O discurso de Ulysses Guimarães na promulgaçáo da Carta continha o seguinte trecho: "foi de audácia inovadora a arquitetura da Constituinte, recusando anteprojeto forâneo ou de elaboração interna".

4. Havia controvérsia em dois aspectos (ARAUJO, 2013): quanto à instauração de uma assembleia exclusiva (adjetivo que não figurava no "Compromisso com a Nação" da Aliança Democrática) e quanto à presença dos 23 senadores eleitos nas eleiçóes de 1982, uma vez que, mesmo com a opção pelo Congresso Constituinte, a delegação por parte do cidadáo-eleitor seria por meio das eleiçóes de 1986 — assim os senadores de 1982 não teriam essa legitimação.

5. O fórum era constituído pelas seguintes entidades: Associação Nacional de Educação (ANDE), Centro de Estudos, Educação e Sociedade (CEDES), Associação Nacional de Pós-Graduação e Pesquisa em Educação (ANPEd), Associação Nacional de Docentes do Ensino Superior (ANDES), Associação Nacional de Profissionais de Administração da Educação (ANPAE), Sociedade Brasileira para o Progresso da Ciência (SBPC), Federação Nacional de Orientadores Educacionais (FENOE), União Brasileira de Estudantes secundaristas (UBES), Sociedade Estudos e Atividades Filosóficas (SEAF), Confederação Geral dos Trabalhadores (CGT), Confederação dos Professores do Brasil (CPB), Central Única dos Trabalhadores (CUT), Ordem dos Advogados do Brasil (OAB), União Nacional dos Estudantes (UNE) e Federação das Associações de Servidores das Universidades Brasileiras (FASUBRA).

6. O regimento interno foi promulgado em 24 de março de 1987, sendo relator o líder do PMDB no Senado Federal, Fernando Henrique Cardoso. Foi alterado em 3 de dezembro de 1987, quando vitoriosa a proposta do Centráo.

7. O Centrão propôs uma reforma do regimento, o que se concretizou em 3 de dezembro de 1987, com a aprovaçáo do substitutivo do deputado Roberto Cardoso Alves - o que gerou a retirada do plenário da maioria dos peemedebistas, por orientação de seu líder, e dos partidos da esquerda. Apesar da reação conservadora, o grupo não tinha a coesão que se supunha e, ao lado de algumas vitórias, sofreu também derrotas importantes: em maio de 1988, foi rejeitada sua proposta para o capítulo da ordem econômica (BONAVIDES \& ANDRADE, 1989).

8. As demais eram a Subcomissão da Ciência e Tecnologia e Comunicação, e a Subcomissão da Família, do Menor e do Idoso.

9. A defesa da inclusão na Constituição de dispositivo que definisse a educação como direito de todo cidadáo e impusesse o dever do Estado de oferecer ensino público e gratuito para todos em todos os níveis uniu expositores como Newton Lima Neto, da ANDES; Miriam Limoeiro Cardoso, da ANDES; Cláudio Boschi, da FBAPEF; Maria Beatriz Luce, da ANPAE; Fernando Fonseca, do Conselho Federal de Educação; Rodolfo Joaquim Pinto da Luz, do CRUB; Rovílson Robbi Brito, da UBES; Elizabeth Camargo, do CEDES; Gisela Moulin Mendonça, da UNE; e Osmar Fávero, da ANPEd (BARROS; ANDRÉS, 2009). 
10. Fala contraditada em seguida pelos constituintes Chico Humberto, Ubiratan Aguiar, Florestan Fernandes, Gumercindo Milhomem e Átila Lira.

11. A área de educaçáo realizou audiências nos dias 23, 28, 29 e 30 de abril, quando ouviu 33 entidades, em um total de 39 depoentes. No dia 13 de maio, foi ouvido, em audiência pública, o ministro da Educaçáo, senador Jorge Bornhausen. No dia 18 de maio, os professores Paulo Freire e Moacir Gadotti visitaram a comissão, tendo sido homenageados pelos constituintes e provocados a declarar suas sugestóes à Nova Carta. No dia 20 de maio, também visitou a comissão o professor Juan Tedesco, da Organização das Nações Unidas para a Educação, a Ciência e a Cultura (Unesco), que apresentou os pontos mais significativos do Projeto Principal da Educaçáo, matéria proposta pela sua entidade aos países da América Latina e do Caribe (BARROS; ANDRÉS, 2009).

12. Em 28 de abril de 1987 (DANC, 1987b, p. 239), ao comparecer à subcomissão, Tomaz Wonghon, da Confederaçáo dos Professores do Brasil (CPB), relatava que, naquele momento, a greve de Sergipe chegava ao $19^{\circ} \mathrm{dia}$, a do Rio Grande do Sul, ao $18^{\circ}$ dia, a do Espírito Santo, ao seu $5^{\circ}$ dia, a do Distrito Federal, ao $27^{\circ}$ dia, e a Pernambuco, ao $17^{\circ}$ dia. Nessa mesma sessão (DANC, 1987b, p. 261), o deputado Gumercindo Milhomem propunha que se oficiasse ao prefeito de São Paulo, Jânio Quadros, a revisão da demissáo de 1.965 funcionários e a abertura de 2.781 processos administrativos em função da greve - posiçáo apoiada pelos constituintes Átila Lira e Octávio Elísio.

13. A representante da ANPAE sugeriu, inclusive, um entrosamento, já no momento inicial, dos trabalhos da Subcomissão de Educação com os trabalhos da Subcomissão de Tributos.

14. Os constituintes Chico Humberto e Octávio Elísio defendiam, respectivamente, 25 e 15\% de aplicação para a União. O Fórum Nacional de Secretários de Educação propunha que a União aplicasse nunca menos de 18\% (DANC, 1987b, p. 212), o Centro de Estudos Afro-Brasileiros (CEAB) propôs que orçamento da Uniáo fosse de, pelo menos, $40 \%$ no período de formação de uma geração (DANC, 1987c, p. 146). A FENEN fez a proposição de maior aumento nos recursos - evidentemente com a possibilidade de que fossem carreados para o setor privado: anualmente, a Uniáo aplicaria nunca menos de $25 \%$ e os entes subnacionais, de $40 \%$ da receita resultante de impostos, na manutenção e no desenvolvimento do ensino (DANC, 1987b, p. 346).

15. A vinculação à manutenção e ao desenvolvimento do ensino não é apenas uma exceção à regra do art. 167, IV, que constitucionalizava o princípio de direito tributário denominado de princípio da não afetação. É muito mais que isso, é um princípio independente: o art. 34, VII, “e”, expressamente afirma ser a vinculaçấo um princípio constitucional sensível, cuja inobservância acarreta, inclusive, a intervenção federal (MARTINS, 2008).

\section{Referências}

AGÊNCIA SENADO. Entrevista com José Afonso da Silva. Agência Senado, 2008.

ARAUJO, C. O Processo Constituinte Brasileiro, a transição e o Poder Constituinte. Lua Nova, São Paulo, v. 88, p. 327-380, 2013. http://dx.doi.org/10.1590/S0102$\underline{64452013000100011}$ 
BACKES, A.L.; AZEVEDO, D.B.; ARAUJO, J. C. Audiências Públicas na Assembleia Nacional Constituinte. A Sociedade na Tribuna. Brasília: Câmara dos Deputados/Ediçóes Câmara, 2009.

BARROS, H.H.D.; ANDRÉS, A. VIII. A- Subcomissão de Educação Cultura e Esportes. In: BACKES, A.L.; AZEVEDO, D.B.; ARAUJO, J.C. Audiências Públicas na Assembleia Nacional Constituinte. A Sociedade na Tribuna. Brasília: Câmara dos Deputados/Ediçóes Câmara, 2009. p. 543-592.

BONAVIDES, P.; ANDRADE, P. História Constitucional do Brasil. Brasília: Paz e Terra, 1989.

BRASIL. Emenda Constitucional no 26, de 27 de novembro de 1985. Convoca Assembleia Nacional Constituinte e dá outras providências. Disponível em: $<\underline{\mathrm{http}}$ ://www.planalto. gov.br/ccivil_03/Constituicao/Emendas/Emc_anterior1988/emc26-85.htm>. Acesso em: 12 jul. 2018.

Constituição de 1988. Disponível em: <http://www.planalto.gov.br/ccivil_03/ constituicao/constituicaocompilado.htm>. Acesso em: 12 jul. 2018.

CALMON, J. Memória Viva da Educação Brasileira. Brasília: MEC/Inep, 1991. v. 2.

CARVALHO, G.A.B. Transição e o colégio eleitoral: o papel da aliança democrática brasileira (1980-1985). Boletim Historiar, n. 13, p. 14-26, jan./fev. 2016. Disponível em: <http://seer.ufs.br/index.php/historiar>. Acesso em: 15 jul. 2018.

DALLARI, D.A. Os direitos fundamentais na constituição brasileira. In: FIOCCA, D.; GRAU, E.R. (Orgs.). Debate sobre a Constituição de 1988. São Paulo: Paz e Terra, 2001.

DIÁRIO DA ASSEMBLEIA NACIONAL CONSTITUINTE (DANC). Suplementos. 16 jul. $1987 \mathrm{a}$.

Suplementos. 17 jul. $1987 \mathrm{~b}$.

. Suplementos. 18 jul. $1987 \mathrm{c}$.

Suplementos. 20 jul. $1987 \mathrm{~d}$.

Suplementos. 10 set. $1987 \mathrm{e}$.

FARENZENA, N. Assembleia Nacional Constituinte de 1987-1988, educação e cidadania. Entrevista com Hermes Zaneti. Revista Brasileira de Politica e Administração da Educação, v. 24, n 2, p. 351-358, maio/ago. 2008.

FERNANDES, F. Memória Viva da Educação Brasileira. Brasília: MEC/Inep, 1991. v. 1.

FLEISCHER, D. Um Perfil Socioeconômico, Político e Ideológico da Assembleia Constituinte de 1987. In: ENCONTRO ANUAL DA ANPOCS, 11., 1987. Anais... Aguas de São Pedro, 1987.

GOMES, M.E. Constituição de 1988, 25 anos. A construção da democracia \& Liberdade de expressão: o Brasil antes, durante e depois da Constituinte. São Paulo: Editora Instituto Vladimir Herzog, 2014. 
GUIMARÃES, U. Discurso de promulgação da Carta de 1988. 1988. Disponível em: <http://www2.camara.leg.br $>$. Acesso em: 12 jul. 2018.

LAMOUNIER, B. Os trabalhos da "Comissão Afonso Arinos". In: FORTES, L.R.S.; NASCIMENTO, M.M. (Orgs.). A Constituinte em debate. São Paulo: Seaf/Sofia, 1986.

MARTINS, P.S. O financiamento da educação e a constituição de 1988: a vinculação de recursos à manutenção e ao desenvolvimento do ensino. In: ARAÚJO, J.C.; PEREIRA JÚNIOR, J.S.; PEREIRA, L.S.; RODRIGUES, R.J.P. (Orgs.). Ensaios sobre impactos da Constituição de 1988 na sociedade brasileira. Brasília: Câmara dos Deputados/Consultoria Legislativa, 2008. v. 1. p. 449-461.

MELCHIOR, J.C.A. Financiamentos da educação: subsídios à Constituinte. Educação Brasileira, v. 7. n. 14. 1. semestre, 1985.

PINHEIRO, M.F. O público e o privado na educação: um conflito fora de moda? In: FÁVERO, O. A educação nas constituintes brasileiras. 1823-1988. 2. ed. Campinas: Autores Associados, 2001.

SOUZA, M.C.C. A Nova República brasileira: sob a espada de Dâmocles. In: STEPAN, A. (Org.). Democratizando o Brasil. Rio de Janeiro: Paz e Terra, 1988.

VELLOSO, J. Investimento público em educação: quanto e onde? Ciência e Cultura, v. 40, n. 4, abr. 1988.

O financiamento da educação na Transição Democrática. In: MELLO, G.N.; VELLOSO, J.; WARDE, M.; SILVA, T.R.; SALGADO, M.U. Educação e Transição Democrática. São Paulo: Cortez/Autores Associados, 1989.

Recebido em 4 de abril de 2018.

Aceito em 3 de outubro de 2018. 